\title{
End-stage renal disease in NIDDM: a consequence of microangiopathy alone?
}

\author{
A .E .G. R aine $\dagger^{1}$, R.W. B ilous ${ }^{2}$ \\ ${ }^{1}$ The R oyal H ospital of St. B artholomew, L ondon, U K \\ ${ }^{2} \mathrm{D}$ iabetes Care Centre, M iddlesbrough G eneral H ospital, M iddlesbrough, UK
}

The number of patients developing end-stage renal disease (ESRD) due to diabetes mellitus is increasing and most of these patients have the non-insulindependent form (NIDDM) [1, 2]. In addition to the need for renal replacement therapy (RRT), such patients also have other diabetic complications affecting the micro- and macrovasculature. Survival, once renal failure is established, remains disappointingly low and significantly lower than for non-diabetic renal failure patients, mainly due to cardiovascular disease [3]. A Ithough the natural history of renal complications has been well-researched in insulindependent (IDDM) patients, there are far fewer studies in NIDDM [4]. Similarly the pathophysiology of diabetic nephropathy has been studied primarily in IDDM . In addition, there is some question as to whether proteinuria in IDDM is diagnostic of diabetic glomerulopathy alone [5-7]. This short report will briefly discuss the present incidence and prevalence of diabetic ESR D and its changing pattern in $E$ urope. Finally, it will comment on whether ESRD in NIDDM is due primarily to microangiopathy.

\section{Worldwide incidence of prevalence of diabetic ESRD}

True incidence and prevalence of diabetic ESRD is difficult to assess because most registry data depend upon referral to an RRT programme. Patients who are not referred because of age or other medical

Corresponding author: D r. R. W. B ilous, D iabetes Care Centre, $M$ iddlesbrough $\mathrm{G}$ eneral $\mathrm{H}$ ospital, $\mathrm{M}$ iddlesbrough, U K A bbreviations: ESRD, End-stage renal disease; IDDM , insulin-dependent diabetes mellitus; NIDDM, non-insulin-dependent diabetes mellitus; RRT, renal replacement therapy; E DTA , E uropean D ialysis and Transplant A ssociation $\dagger$ D eceased complications will not, therefore, be registered. The acceptance rate of diabetic ESR D patients to RRT programmes in 1992 is shown in Table 1. The E uropean average of 6 per million population is one tenth that of the U nited States, although there is a wide range both between and within individual countries. Part of this variation is a reflection of ethnic case mix. Diabetes and its complications are common in A sian patients [8] which partly explains why the acceptance rate in St. Bartholomew's Renal U nit in L ondon is five times the national average (it is situated in an area with a high number of $A$ sians). A frican-A mericans also have a higher prevalence of diabetes and ESRD, and comprise a large proportion of patients on R RT in the U nited States [9]. M ost Japanese patients with diabetes have NIDDM, but much lower rates of cardiovascular disease than their western counterparts [10]; thus, many more may survive to develop renal failure and need R RT.

The worldwide incidence of new enrolment in RRT is showing a similar trend upwards, however, with over one third of such patients in the U nited States [2] and one fifth in E urope [1] having diabetes as their primary cause of ESR D.

Changing patterns of IDDM and NIDDM ESRD in E urope

The E uropean Dialysis and Transplant A ssociation R egistry (EDTA) probably has the most complete longitudinal data available on the changing patterns of referral for R RT. O ver the decade 1982-1992, the increase in patient acceptance was almost exclusively in the age range 45-65 and 65 + years [1]. The increase in number of patients with diabetic ESRD is also within these age ranges and is likely to be predominantly NIDD M. Since 1983, the EDTA R egistry has coded separately for IDDM and NIDDM. The 
Table 1. A cceptance of diabetic E SR D for R RT in 1992

\begin{tabular}{ll}
\hline & per million population \\
\hline USA (1990) & 62 \\
Japan & 50 \\
Canada & 24 \\
EDTA & 6 \\
Austria & 21 \\
Denmark & 14 \\
Netherlands & 9 \\
London (1994) (76\% NIDD M ) & 34 \\
\hline
\end{tabular}

Table 2. Why is there such disparity in reporting of non-diabetic renal disease in NID DM?

- Small sample numbers?

- Selection bias (retrospective studies)?

- I schaemic glomerular lesions in elderly NID D M patients?

- True racial/geographical differences?

- Variations in histopathological classification?

reported variation in the proportion of patients with ESR D coded as IDDM or NIDDM needs careful interpretation however, as many NIDDM patients treated with insulin are probably coded as IDDM. Nonetheless, certain differences stand out, e. g. three to four times more IDDM than NIDDM patients with $E$ SR D in Scandinavia; but near equality in Germany, A ustria and Southern E uropean Countries [1]. These countries are now accepting over 20 NIDDM patients per million population per year and this figure is projected to double by the year 2000 . O verall for E urope, total annual acceptance of diabetic patients for R RT has risen from approximately 2000 in 1983 to over 4000 in 1990 and the proportion coded with NIDDM has risen from approximately $20 \%$ to over $40 \%$ [1].

\section{ESRD in NID D M : microangiopathy alone?}

The histological appearances of diabetic glomerulopathy are identical in IDDM and NIDDM patients with nephropathy. Indeed, most of the early descriptions were in mixed populations of diabetic patients as insulin was the only available treatment [11-13]. M ore recently, studies at the light and electron microscope level in carefully defined IDDM and NIDDM patients with nephropathy have failed to show any consistent differences [14].

These observations imply a similar pathophysiology in patients with either type of diabetes, but recent data have demonstrated intriguing differences in the function of the microvasculature in IDDM and NID D M . Jaap and Tooke [15] have shown that capillary pressure and fluid permeability are normal in NIDDM but increased in IDDM patients. They propose that the hyperinsulinaemia that is characteristic of NIDDM may underpin these differences. The pathophysiological significance of these observations remains to be elucidated however.

A more controversial issue is how often proteinuria in NIDDM patients signifies diabetic or some other glomerulopathy. This topic is discussed at greater length by Steen-O Isen and M ogensen elsewhere in this issue, but in a series of 31 NIDDM patients who were consecutively referred to the St. $B$ artholomew's $H$ ospital R enal U nit with varying degrees of renal impairment, 29 had a primary diagnosis of diabetic glomerulosclerosis [16]. Table 2 outlines some of the reasons why we feel there is a discrepancy in reported frequency of non-diabetic glomerular pathology in NID D M patients. O ur assessment is that non-diabetic renal disease accounts for less than $10 \%$ of proteinuria in NIDDM patients.

\section{Summary}

1. D iabetes (primarily NIDDM ) is the commonest single cause worldwide of treated E SRD.

2. $O$ ver the past 15 years there has been a 20 -fold increase in the acceptance of diabetic patients for R RT in E urope.

3. There are large international variations in the prevalence of IDDM and NIDDM ESRD which may have a genetic/ethnic basis.

4. The wide variation in reported frequency of non-diabetic renal disease in NIDDM patients with proteinuria may be a reflection of referral patterns and probably accounts for less than $10 \%$ of cases.

5. The nature of microangiopathy in NIDD M and any possible differences with IDDM need further study.

A cknowledgements. Tragically Professor R aine was taken ill prior to the NIDD M Symposium in Stockholm and died before he could complete the manuscript relating to his presentation. The short paper appearing here was drafted by R.W. B . using the detailed notes made by Professor $R$ aine and kindly provided by his secretary. R.W.B. accepts full responsibility for the content of the paper.

M y thanks to MS. S. Cesar who provided me with Professor $\mathrm{R}$ aine's notes and to MS. S. Barsoum who typed the manuscript.

\section{References}

1. G eerlings W, Tufveson G, Ehrich JHH et al. (1994) R eport on management of renal failure in E urope, XXIII. Nephrol Dial Transpant 9 [Suppl 1] 6-25

2. U SR D S R eport (1994) IV. Incidence and causes of treated E SR D. A mer J Kid D is 24 [Suppl 2]:S48-S56

3. Koch M, Thomas B, T schope W, Ritz E (1993) Survival and predictors of death in dialysed diabetic patients. Diabetologia 36: 1113-1117

4. D eckert T, B orch-J ohsen K, G renfell A (1984) E pidemiology and natural history of diabetic nephropathy. In: Pickup JC, Williams G (eds) Chronic complications of diabetes. B lackwell Scientific Publications O xford pp 139-145

5. Parving H-H , Gall M-A, Skott $P$ et al. (1992) Prevalence and causes of albuminuria in non-insulin-dependent diabetic patients. K idney Int 41: 758-762 
6. R ichards NT, G reaves I, L ee SJ, H owie A J, A du D, M ichael J (1992) Increased prevalence of renal biopsy findings other than diabetic glomerulopathy in type II diabetes mellitus. Nephrol Dial Transplant 7: 397-399

7. G ambara V, M ecca G, R emuzzi R , B ertani T (1993) H eterogeneous nature of renal lesions in type II diabetes. J A m Soc N ephrol 3: 1458-1466

8. Burden A C, M cNally PG, Feehally J, Walls J (1992) Increased incidence of end-stage renal failure secondary to diabetes mellitus in A sian ethnic groups in the $U$ nited Kingdom. Diabet Med 9: 641-645

9. Cowie CC, Port FK, Wolfe R A, Savage PJ, M oll PP, H awthorne V M (1989) D isparities in incidence of diabetic endstage renal disease according to race and type of diabetes. N Engl J Med 321: 1074-1079

10. Sasaka A , Kamado K , H orruchi N (1978) A changing pattern of causes of death in Japanese diabetics. O bservations over 15 years. J Chron D is 31: 433-444
11. B ell ET (1953) R enal vascular disease in diabetes mellitus. Diabetes 2: 376-389

12. G ellman DD, Pirani CL, Soothill JF, M uehrcke R C, Kark R M (1959) Diabetic nephropathy: a clinical and pathological study based on renal biopsies. M edicine (Baltimore) 38: 321-367

13. Hatch, FE, Watt M F, K ramer NC, Parrish M D, H owe J $S$ (1961) Diabetic glomerulosclerosis. A long-term follow-up study based on renal biopsies. A m J M ed 31: 216-230

14. O sterby R, G all M-A, Schmitz A, Nielsen FS, Nyberg G, Parving H-H (1993) G lomerular structure and function in proteinuric type 2 (non-insulin-dependent) diabetic patients. D iabetologia 36: 1064-1067

15. Jaap A J, Tooke J E (1995) Pathophysiology of microvascular disease in non-insulin-dependent diabetes. Clin Sci 89: 3-12

16. M acdougall C, Lightowler C, O ommen R et al. (1994) Prospective study of renal biopsy findings in non-insulin-dependent diabetics. N ephrol D ial Transplant 9: 1680-1681 